Texas A\&M University- San Antonio

Digital Commons@ Texas A\&M University-San Antonio

History Faculty Publications

College of Arts and Sciences

2012

\title{
Beveled Projectile Points and Ballistics Technology
}

C. P. Lipo

R. C. Dunnell

Michael J. O'Brien

Texas A\&M University-San Antonio, Mike.Obrien@tamusa.edu

V. Harper

J.Dudgeon

Follow this and additional works at: https://digitalcommons.tamusa.edu/hist_faculty

Part of the Anthropology Commons

\section{Repository Citation}

Lipo, C. P.; Dunnell, R. C.; O'Brien, Michael J.; Harper, V.; and Dudgeon, J., "Beveled Projectile Points and Ballistics Technology" (2012). History Faculty Publications. 16.

https://digitalcommons.tamusa.edu/hist_faculty/16

This Article is brought to you for free and open access by the College of Arts and Sciences at Digital Commons @ Texas A\&M University- San Antonio. It has been accepted for inclusion in History Faculty Publications by an authorized administrator of Digital Commons @ Texas A\&M University- San Antonio. For more information, please contact deirdre.mcdonald@tamusa.edu. 


\title{
BEVELED PROJECTILE POINTS AND BALLISTICS TECHNOLOGY
}

\author{
Carl P. Lipo, Robert C. Dunnell, Michael J. O’Brien, Veronica Harper, and John Dudgeon
}

\begin{abstract}
Explanations for beveled blade edges on projectile points have been debated in North America archaeology since the first systematic description of lithic assemblages in the nineteenth century. Debate has centered around two opposing perspectives. One views beveled edges as features of projectile points that cause them to spin during flight. The other views beveling as a product of edge resharpening that is done unifacially to conserve scarce resources. Here we use a fluid-dynamics model to simulate the effect beveling has on projectiles. Expectations derived from this modeling are evaluated using windtunnel experiments. Our findings indicate that beveling produces in-flight rotation that serves as a means of increasing accuracy in relatively low-velocity flight paths.
\end{abstract}

Las explicaciones para biseló orillas de hoja en puntas de proyectil han sido debatidas en la arqueología de Norteamérica desde la primera descripción sistemática de colecciones de lithic en el siglo XIX. El debate ha concentrado en dos perspectivas opuestas. Uno ve biseló orillas como características de proyectiles que causan ellos girar durante vuelo. La otra perspectiva ve biseles como productos del afilado de orilla que es hecho para conservar unifacially recursos escasos. Para evaluar estas dos vistas, nosotros utilizamos un modelo de la líquido-dinámica para simular el efecto que bisela tiene en proyectiles. Las esperanzas derivadas de esta profesión de modelo son evaluadas utilizar experimentos de túnel aerodinámico. Nuestras conclusiones indican que biselando productos rotación en vuelo y que tal rotación de puntos arrojadizos, que sirve para precisión creciente en relativamente trayectorias de vuelo de bajo-velocidad.

$\mathrm{O}$ ne curious feature of many projectile points from the American Midwest and Southeast is the shape of their cross section. Instead of having edges formed by bifacial flaking, these points have beveled edges created by removal of flakes at steep $\left(>40^{\circ}\right)$ angles. A flintknapper would remove flakes from one edge of a face, then turn the biface over and repeat the process on the other edge. Thus, instead of the common lenticular cross section seen in most bifaces, beveled bifaces have a parallelogramshaped cross section (Figure 1). When viewed on end, the beveled edges give the bifaces a characteristic "twist" in the direction of the beveling.

Beveled-edge projectile points enter the archaeological record during the Late Paleoindian-Early Archaic period, ca. 11,900-10,000 calibrated years B.P. (cal B.P.). Beveling is a common characteristic of the large Dalton group of projectile points, which, in addition to Dalton, includes the Hardaway and Greenbrier types, and on slightly later forms such as Hardin Barbed, Thebes, Lost Lake, St. Charles, Decatur, and Rice Lobed. Beveling re-emerged briefly during the Early Woodland period, ca. 2750-2200 cal B.P., but not nearly to the degree seen millennia earlier. It disappeared a few hundred years later.

Here we explore the dynamics related to the use of beveled points, our hypothesis being that beveling affects flight aerodynamics by causing projectile points to rotate. We show that this rotation contributes to the accuracy of flight paths under particular circumstances. To do this, we demonstrate that rotation occurs in simulated modeling using computational fluid dynamics as well as in controlled wind-tunnel experiments. In

Carl P. Lipo - Department of Anthropology and IIRMES, California State University Long Beach, 1250 Bellflower Blvd., Long Beach, CA 90840 (clipo@csulb.edu)

Robert C. Dunnell — Department of Anthropology, Mississippi State University, Mississippi State, MS 39762 (deceased)

Michael J. O'Brien D Department of Anthropology, University of Missouri, Columbia, MO 65211

Veronica Harper $\square$ Cardno JF New, 3901 Industrial Boulevard, Indianapolis, IN 46254

John Dudgeon $=$ Department of Anthropology, Idaho State University, 921 S. $8^{\text {th }}$ Avenue, Pocatello, ID 83209 


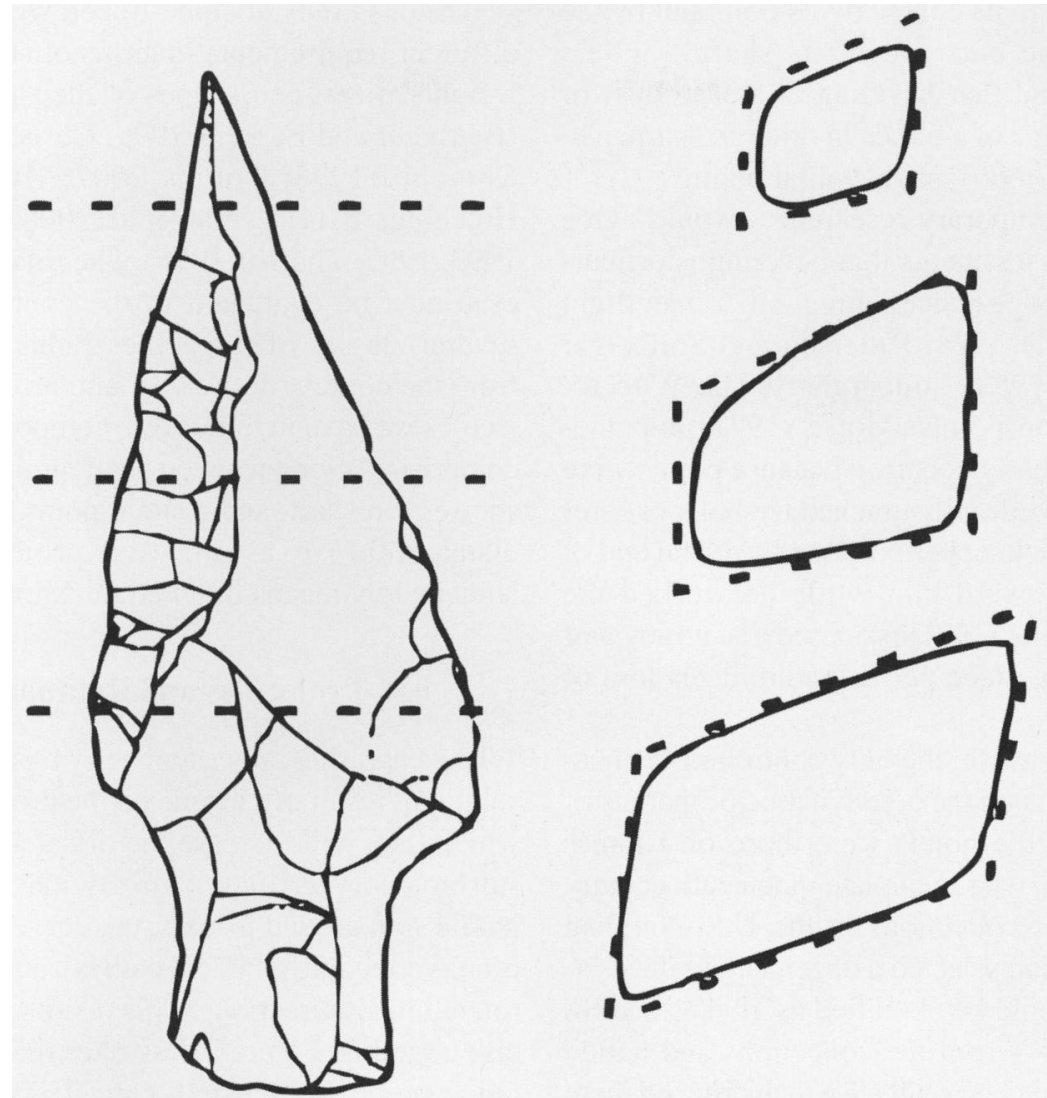

Figure 1. Sketch of a beveled biface and three cross-sections, illustrating how the angle of bevel changes along the blade.

addition, we examine the mechanics of flight and rotation and examine the potential aerodynamic benefits of the spin of a projectile point while in flight. Finally, we discuss the implications of these experiments for documenting and explaining variability of projectile points with respect to their environment of use. To place our work in perspective, we briefly review below some explanations that have been advanced for projectilepoint beveling. As we will see, we are not the first to study the aerodynamic potential of beveling.

\section{Some Explanations of Beveled Points}

Speculation on the purpose of beveling on pointed bifaces extends back to the earliest systematic observations of North American archaeology. For example, Squier and Davis (1848) remarked that "arrowheads" they found were chipped so that their edges formed a large angle with their planes, as if to give them revolving or tearing motion. Morgan (1851) noted that Iroquois "arrow-heads" were occasionally found with a twist to make the arrow revolve. Later researchers repeated this account (Abbott 1877; Beckwith 1879; Carr and Shaler 1876; Fairbank 1864; Tait 1874), some speculating that rotation resulted in greater damage on impact (Abbott 1881:99; Jones 1873:255) or in straighter flight and accuracy by averaging curvatures in shafts (Wallace 1887:666).

Other researchers challenged these assertions. Holmes (1896:177-178) argued that contemporary archers did not use beveling to achieve rotation, and he reasoned that rotation is unnecessary and even an undesirable feature for projectiles that must pass through the ribs of game and enemies. Fowke (1902:673-674) challenged whether any rotation caused by a bevel would be sufficient to provide a benefit to the flight path. Sellers (1886:884-885) argued that "an arrow is not di- 
rected or held to its course by its point but by the feathers at the butt end of its shaft." Sellers claimed instead that beveling is the product of flaking one edge of a biface in order to sharpen it. Packard (1887:666) made similar claims.

Most contemporary researchers would agree with earlier assessments that beveling is primarily related to edge resharpening rather than flight (e.g., Goodyear 1974; Patterson and Sollberger 1990; Smith 1953; Sollberger 1971). With respect to Dalton points, Morse (1971) hypothesized that beveling occurred because points were resharpened while still attached to shafts or foreshafts, with the knapper pointing the distal end of the weapon toward him while he worked the edges. Sollberger (1971) proposed that removal of flakes from one face per side minimizes loss of raw material.

Prior to our work, the only controlled, replicable experiments on the aerodynamic properties of beveled projectile points were those of Thomas Wilson (1898), who in the late nineteenth century was curator of collections in the U.S. National Museum. Wilson selected a dozen large bifaceswhat today would be classified as Thebes and St. Charles points-from the collections and hafted them onto unfletched shafts. He then dropped them from atop the Smithsonian Castle and observed that the composite pieces rotated as they fell. In addition, he experimented with points in a rig that could be pulled through a water tank. Again, the bifaces rotated. Finally, Wilson constructed a crude wind tunnel in which he could vary the conditions to which beveled points were subjected. As in previous tests, the bifaces rotated, and the rate of the rotation varied with wind speed.

Decades later, Smith (1953) tried to observe rotation in projectiles by (1) launching an arrow straight up in the air and attempting to watch it spin (or not) on its descent and (2) describing the flight of arrows that were shot from in front of an observer. Neither of these experiments is relevant to the archaeological records of the Midwest and Southeast, which make it clear that beveling appears not on arrow points but on dart points. By the time the bow and arrow appeared in those regions, ca. 1300 cal B.P. (Kelly et al. 1984) or slightly earlier (Blitz 1988; O'Brien and Wood 1998; Shott 1993), beveling of projectile points had long disappeared.
Various kinds of stone-tipped weaponry have different requirements in terms of shafts and the weights, sizes, and shapes of their pointed ends (Bettinger and Eerkens 1999; Christenson 1986; Churchill 1993; Collins 2007; Hughes 1998; Hutchings 2011; Lyman et al. 2008, 2009; Shott 1993, 1997; Thomas 1978). The rotation hypothesis must be evaluated in the context of these several classes of projectiles rather than solely from the context of the bow and arrow. The projectiles we have in mind were composite weapons comprising a long wooden shaft, probably a much shorter foreshaft, and a stone point hafted to the distal end. We assume the projectiles were launched by means of an atlatl (Shott 1997).

\section{Projectiles and Rotation}

When a dart flies, any asymmetry that exists in the shaft will result in a torque on the projectile point, which then will increase the offset angle and result in a curved flight path. By making the projectile spin around its axis, the curved flight path is converted into a helical path because the bias is rotated in all directions. This results in more precise targeting. Figure 2 illustrates the effect of rotation on projectile flight path. To describe how beveling can cause a projectile to spin, consider the simple case where airflow moves directly along the shaft, that is, the projectile flies perfectly straight. In this situation, shear drag acts at right angles to the cross section of the projectile (Figure 3). Shear drag is a result of the projectile moving through the air and the kinetic energy required to move the air out of the way so that the projectile can pass. It is proportional to the velocity of the object and the size of the cross section. The "pile" - the sharp piece (here a stone point) at the distal end of a projectile-usually forms the largest cross section.

Bevels present a face on the pile that is angled and, consequently, drag force is no longer normal to the shaft (Figure 4). One component of the drag force on the bevel acts to slow the projectile down, and another component generates a torque on each bevel at a right angle to the bevel face. This torque acts to rotationally accelerate the projectile. Importantly, this rotation occurs using the same drag that would be present without beveling. Thus, rotation comes for "free," given that the 


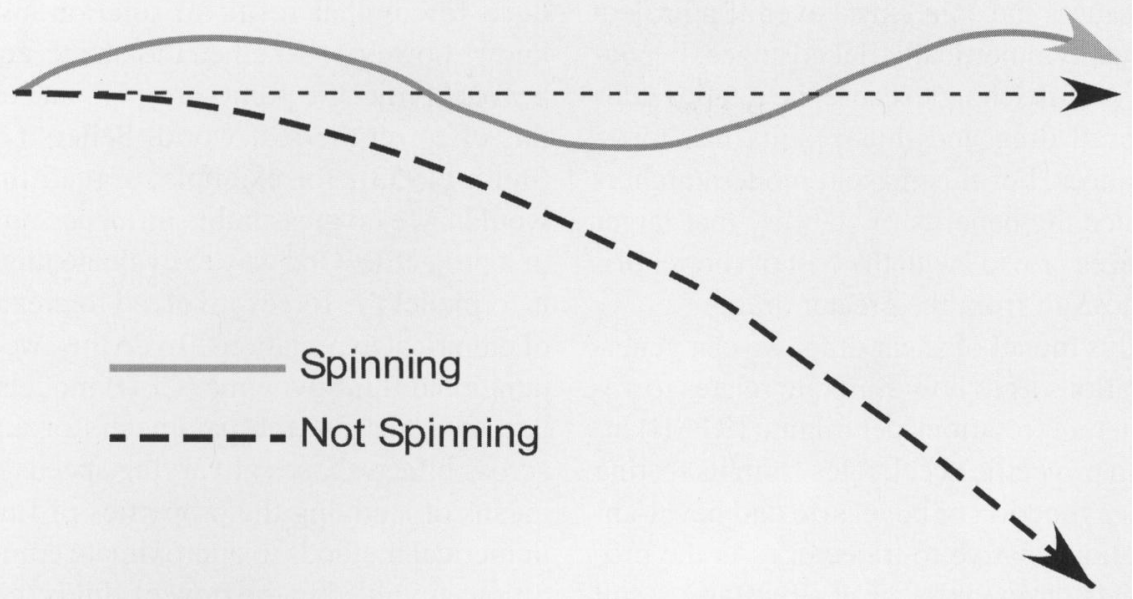

Figure 2. The effect that spinning has on a projectile's path (fine dashed line). Rotation of the projectile averages out variability caused by asymmetric shafts and points (solid line). Nonspinning projectiles (thick dashed line) will drift in the direction of unbalanced weight.

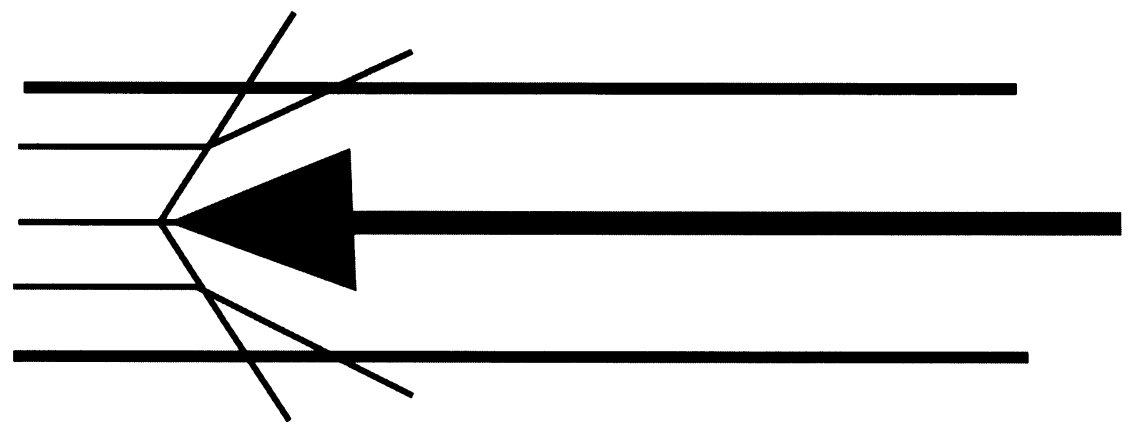

Figure 3. Shear drag is caused by the interaction of the projectile-point cross section and wind velocity.

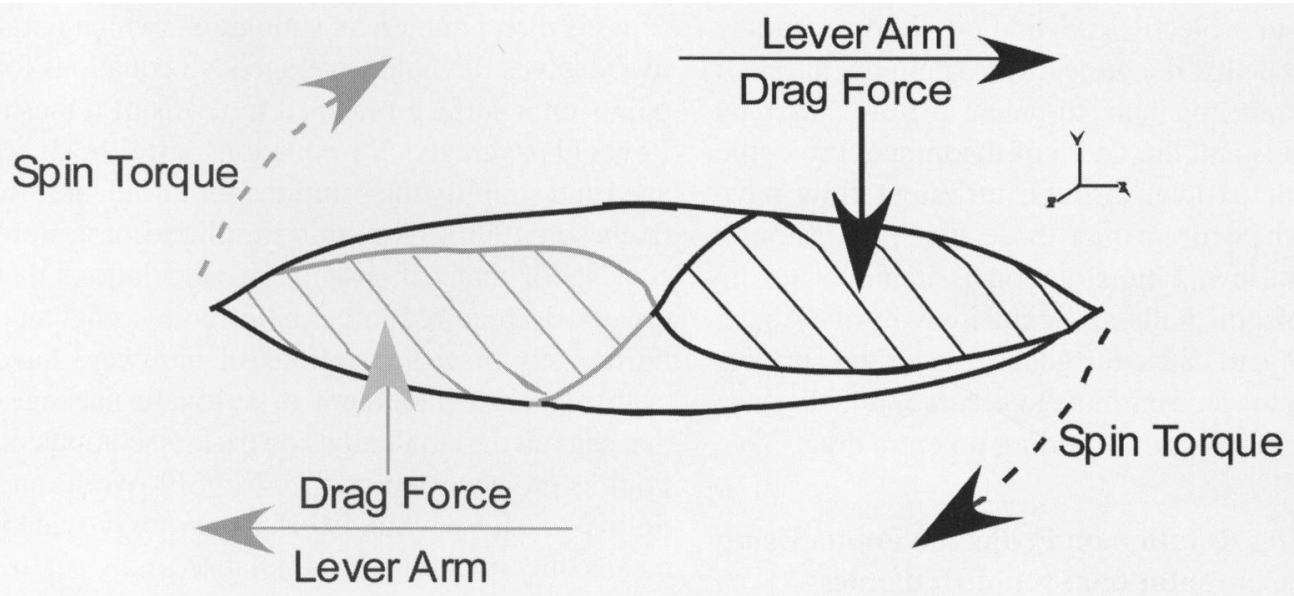

Figure 4. Shear drag on the opposing beveled faces produces torque, which causes rotation. 
drag that causes the spin exists even if a projectile point has symmetrically flaked edges. In contrast, the use of fletching to cause the rotation adds to the overall drag and thus results in shorter flight distances. For this reason, modern archers must balance the benefits of stability that larger fletching sizes provide with the cost of shorter distances that result from the greater drag.

Using this model of shear drag, we can generate expectations as to how spin rate relates to velocity. Spin rate (rotations per minute [RPM]) increases as a projectile accelerates from its resting position as a function of bevel size and bevel-angle orientation relative to trajectory. As the projectile travels through the air, it slows as a result of drag effects caused by the cross section of the pile. Initially, the direction of the net airflow onto the bevel is along the path that is parallel to the shaft. As the projectile spins faster, however, the bevels move faster and faster relative to a right angle to the shaft. The net airflow direction is the sum of the air velocity and the bevel velocity. As the spin rate increases, the net air flow direction rotates until at some combination of projectile speed and projectile RPM, the direction of the net air flow will be parallel to the bevel faces, at which point the spin acceleration will be zero. The projectile will have reached a terminal RPM and will not spin faster at that velocity. Thus, our model specifies that rotation rate increases as a function of velocity, bevel surface area, and angle of intersection.

Increased rotation rate provides an additional benefit to projectiles beyond providing accuracy in flight paths. If a projectile is spinning, the shaft begins traveling in the turbulent airflow caused by the bevels and the width of the biface. Projectile shafts that travel through turbulent flow have lower shear drag than those that pass through laminar flow. This situation is identical to the flight of golf balls and explains why they have dimples - to cause turbulent flow at the surface. Thus, spin can contribute to accuracy and distance of a flight path while adding no extra drag.

\section{Modeling Rotation on Projectile Points Using Computational Fluid Dynamics}

Given this simplified understanding of aerodynamics, it is clear that beveled edges should pro- duce forces that result in rotation. We do not know, however, whether the shape and size of beveled projectile points are adequate to produce this effect in the real world. Sellers (1886) and Smith (1953), for example, argued that bevels would have no measurable influence on the flight of a projectile. One way to evaluate this assertion is to model the forces involved to create a series of empirical expectations. To do this, we use computational fluid-dynamic (CFD) models to simulate and measure the parameters of air moving across biface shapes at varying speeds. CFD is a means of studying the properties of fluids using numerical methods to approximate complex conditions involved in the flow of fluids (e.g., gases, liquids) around solid objects. The fundamental basis of CFD is a set of equations known as the Navier-Stokes (NS) equations, which can be used to define any single-phase fluid flow. NS equations are based on the application of Newton's second law of thermodynamics to fluid motion and are expressed as nonlinear partial differential equations that have the useful property of modeling rates of change (Acheson 1990). These equations form the basis of aerodynamic engineering and allow researchers to study phenomena such as lift in airplane wings and the efficiency of automobile shapes traveling at variable speeds. Consequently, CFD is ideally suited to studying the properties of beveling on variability in how shape influences flow parameters for projectile points.

The most direct approach to solving turbulent flows is direct numerical simulation, which iteratively solves Reynolds-averaged NS equations for points on a surface modeled in terms of a mesh. Reynolds-averaged NS equations are time-averaged and simplify the solutions for turbulent flow (Acheson 1990). Even this simplified procedure consists of many thousands of calculations that previously required large mainframe computers. Fortunately, new generations of hardware have enabled the development of software packages that can run the simulations on desktop computers. For this project, we used COSMOSFloWorks and SolidWorks (www.solidworks. com) to provide a means of conducting the simulation and visualizing the results. SolidWorks is capable of constructing and rendering three-dimensional representations of bifaces, and COSMOSFloWorks is a 
fluid-flow simulation tool that integrates with the SolidWorks modeling application.

In our experiments, we created models to represent beveled projectile points using the measurements from projectile points obtained by the senior author (Figure 5). We then subjected these models to CFD simulations where wind velocity directed along the long axis of a projectile point was systematically increased from 5 to 60 meters per second $(\mathrm{m} / \mathrm{s})$, a range that covered the known velocity of arrows, darts, and spears (Hughes 1998). We measured airflow trajectories in directions perpendicular to the long axis as a means of detecting the potential for biface rotation. Figure 6 presents simulation visualizations of flow trajectories. Areas of increased wind pressure occur in the locations that are expected from the shear-drag model previously described.

Figure 7 shows a cross section of air-flow trajectories measured relative to the $y$-axis of the model when airflow is set to $30 \mathrm{~m} / \mathrm{s}$ relative to the $\mathrm{z}$-axis (or long axis of the biface). The red and yellow highlight areas of increased relative wind velocity, and the blue reflects areas of decreased relative wind velocity. As predicted by our shear-drag hypothesis, the opposing directions of air velocity on opposite sides are consistent with expectations of airflow that would result in rotation. This result is also shown in an examination of the forces acting on the beveled faces. Figure 8 displays the total force acting in the normal direction on each beveled face as we increased wind velocity from $5 \mathrm{~m} / \mathrm{s}$ to $60 \mathrm{~m} / \mathrm{s}$. Note that consistent with our shear-drag model, the forces on each bevel are in opposing directions and value. Thus, the force of the wind creates measurable forces that can potentially cause projectiles to spin.

\section{Wind-Tunnel Experiments}

Results of our CFD simulations support the idea that beveling on bifaces is potentially capable of producing the forces required to cause rotation at speeds consistent for prehistoric projectiles, but we still need to show that real-world projectiles work in this manner. To evaluate this proposition, we ran a series of experiments using modeled and prehistoric beveled bifaces in a low-speed wind tunnel with a maximum generated wind speed of $30 \mathrm{~m} / \mathrm{s}$ (Figure 9 ).
For our initial experiments, we created simplified model projectile points from acrylic that matched the dimensions of prehistoric examples used in the CFD simulation (Figure 6). Wind velocity was measured using an ultrasonic anemometer, and rotation rate was recorded using a handheld electronic tachometer. We increased wind velocity systematically from $0 \mathrm{~m} / \mathrm{s}$ to $30 \mathrm{~m} / \mathrm{s}$, the fastest speed for which our wind tunnel could produce laminar flow. Results of the experiment, shown in Figure 10, meet the expectation of the shear-drag model. Our initial hypothesis is, therefore, not falsified: Rotation (revolution) rate increases as a function of wind velocity, bevel surface area, and angle of intersection. Beveled projectile points rotate when propelled through air.

One might ask whether the force created by the beveled points is adequate to spin a shaft to which it is attached, given that the shaft has mass and some resistance resulting from skin drag along its surface. Assuming the shaft is smooth, we can estimate that the resistance to rotation velocity $(\omega)$ will be proportional to the viscosity of air $(\mu)$ integration of the surface around the circumference of the shaft, for the entire cylinder of length $L$ and circumference $2 * \pi *$ radius $(R)$ :

$$
F=\int-\mu \omega R d \theta d L=-2 \pi \mu \omega R L .
$$

If, for example, a projectile shaft is $1 \mathrm{~m}$ long and $1 \mathrm{~cm}$ in radius and is thrown at sea level with an air temperature of ca. $20^{\circ} \mathrm{C}$ (when $\mu$ equals $1.985 \mathrm{~kg} / \mathrm{m} \mathrm{s} \times 10^{-5}$ ), the resistance to a rotation of 5 revolutions/second is $6.2360 \times 10^{-6} \mathrm{~N} \bullet \mathrm{m} / \mathrm{s}$ $(\mathrm{N} \bullet \mathrm{m}=$ newton meter, a unit of torque), which is much smaller than the ca. $.0025 \mathrm{~N} \bullet \mathrm{m} / \mathrm{s}$ created on each opposing face of the simulated projectile point (Figure 8) when traveling at $30 \mathrm{~m} / \mathrm{s}$.

The actual skin drag preventing rotation is likely even smaller than this value because the turbulence caused by the biface at the front end of the shaft will disrupt the laminar flow along the surface of the shaft, making it easier for the entire projectile to rotate. The faster the spin, the less force required to overcome the resistance that the surface of the shaft will have for rotation.

\section{Explaining Projectile-Point Beveling}

The experiments point to a functional explanation of beveling for at least some pointed bifaces: it is 

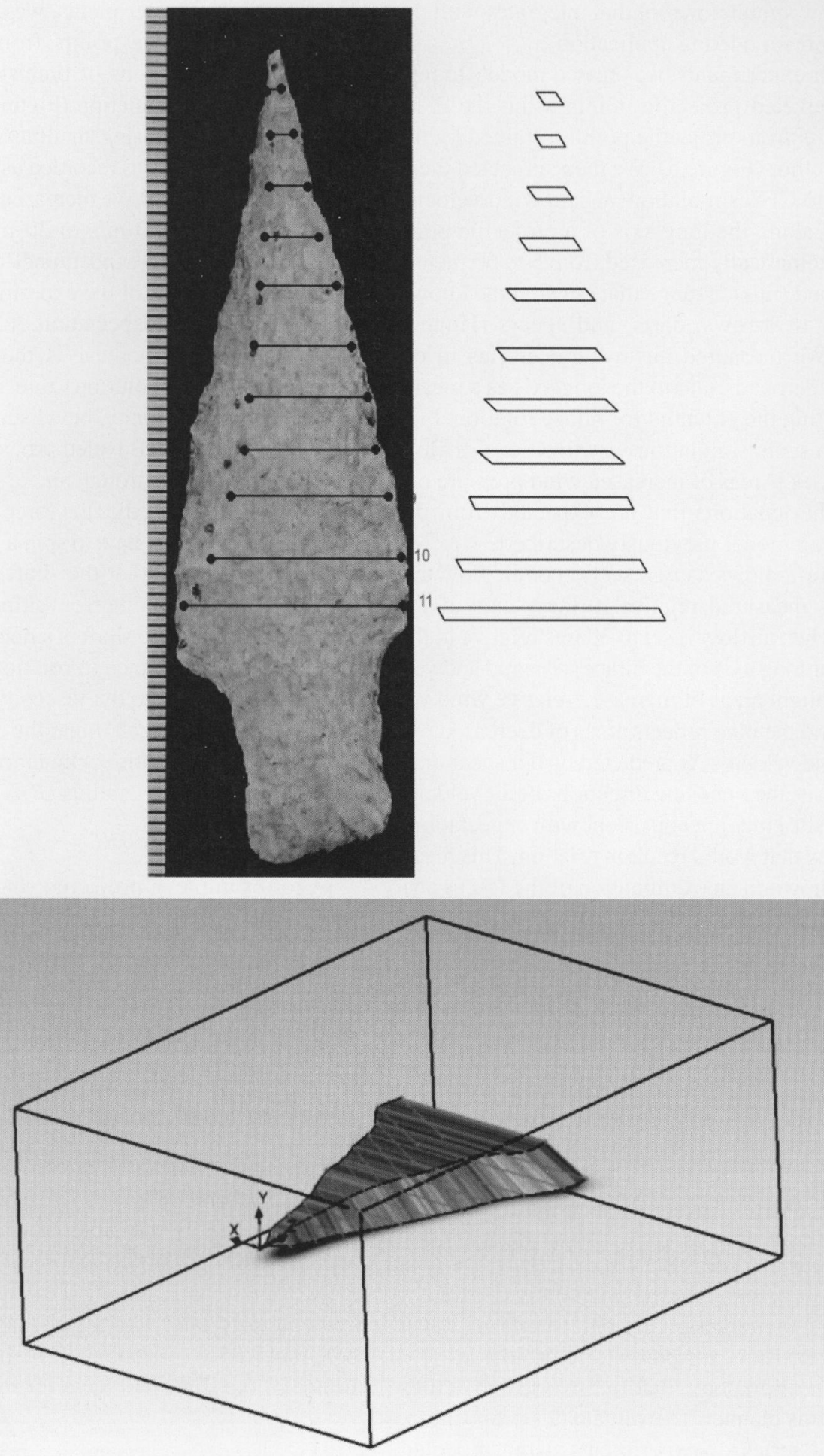

Figure 5. Model of a biface. Using measurements made from a prehistoric beveled projectile point (top), we created a model for the SolidWorks COSMOSFlowWorks CFD simulation (bottom). 

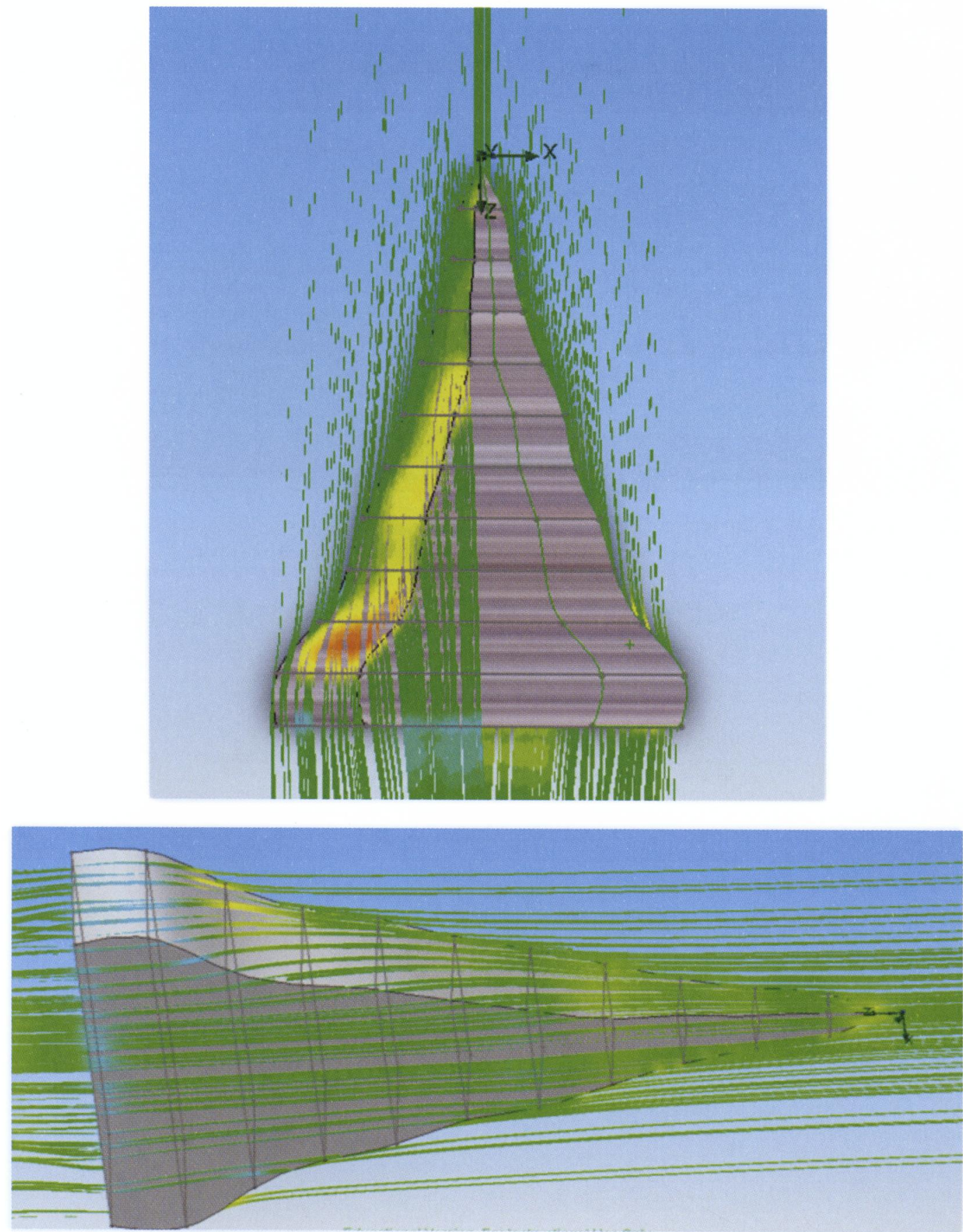

Figure 6. CFD simulation visualizations of flow trajectories. Simulations were run using wind velocity of 5-60 meters per second in $5 \mathrm{~m} / \mathrm{s}$ increments. Green lines show the trajectories of air across the biface at $30 \mathrm{~m} / \mathrm{s}$. Red and yellow highlight areas of increased wind pressure (measured in pascals [Pa], equivalent to $1 \mathrm{~N} \cdot \mathrm{m}$ [newton meter, a unit of torque). Increased air pressure occurs along the beveled faces, as would be expected by the shear-drag model described in the text. 


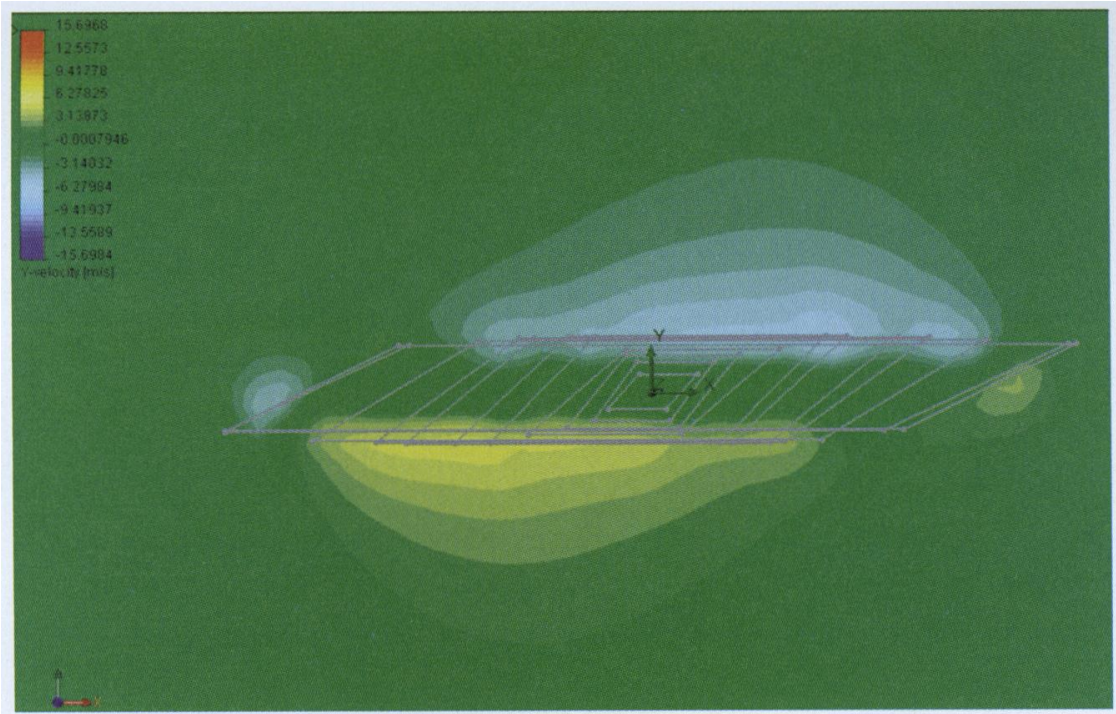

Figure 7. Cross section of airflow trajectories along the $y$-axis of the model when air flows along the z-axis at $30 \mathrm{~m} / \mathrm{s}$. Red and yellow highlight areas of positive velocity along the $y$-axis, and blue reflects negative velocity along the $y$-axis.

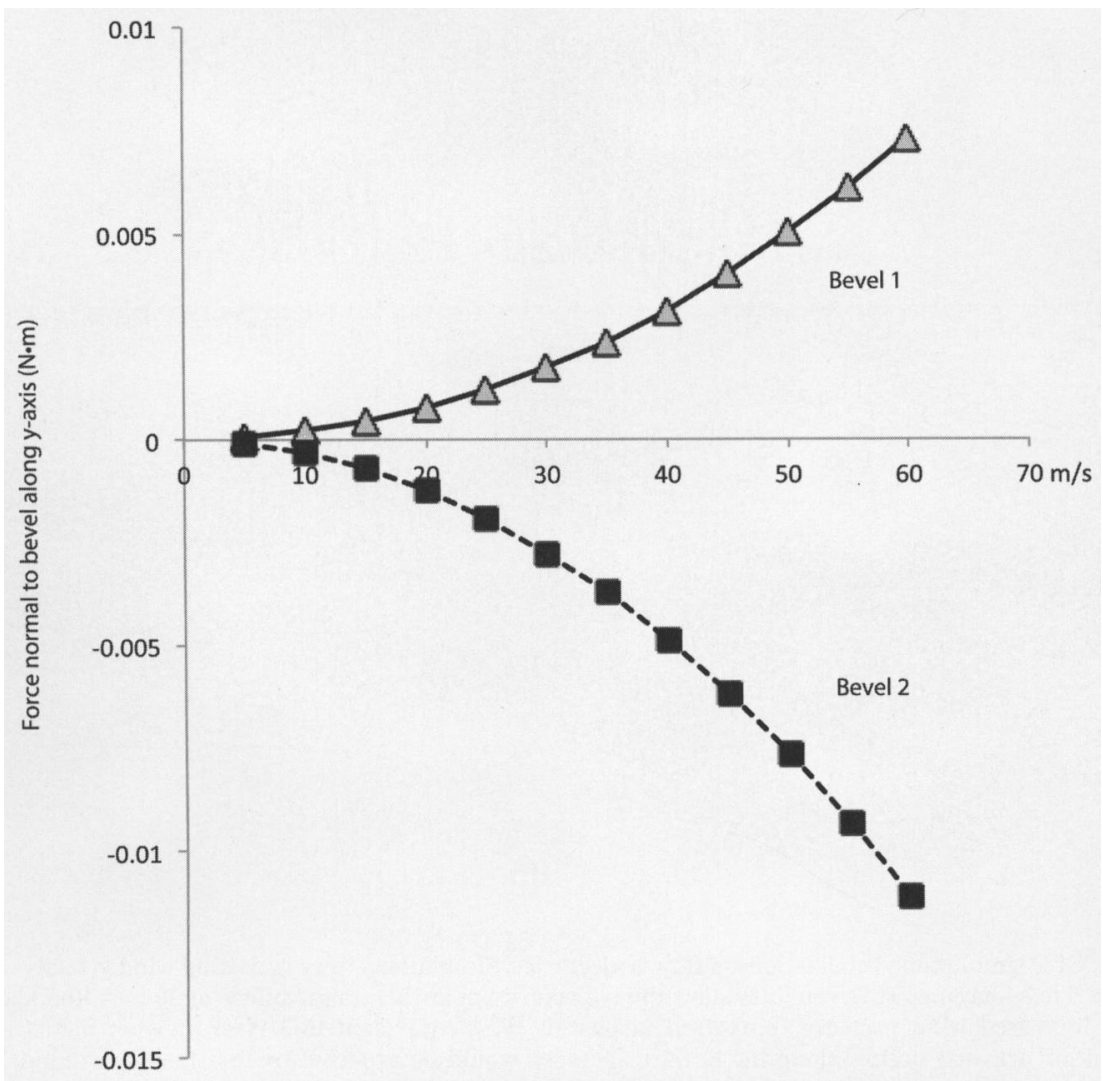

Figure 8. The total amount of force $(\mathrm{N} \bullet \mathrm{m})$ on each beveled face of a projectile point as wind velocity is increased from 5 $\mathrm{m} / \mathrm{s}$ to $60 \mathrm{~m} / \mathrm{s}$ during the CFD simulation ( $\mathrm{N} \cdot \mathrm{m}=$ newton meter, a unit of torque). 


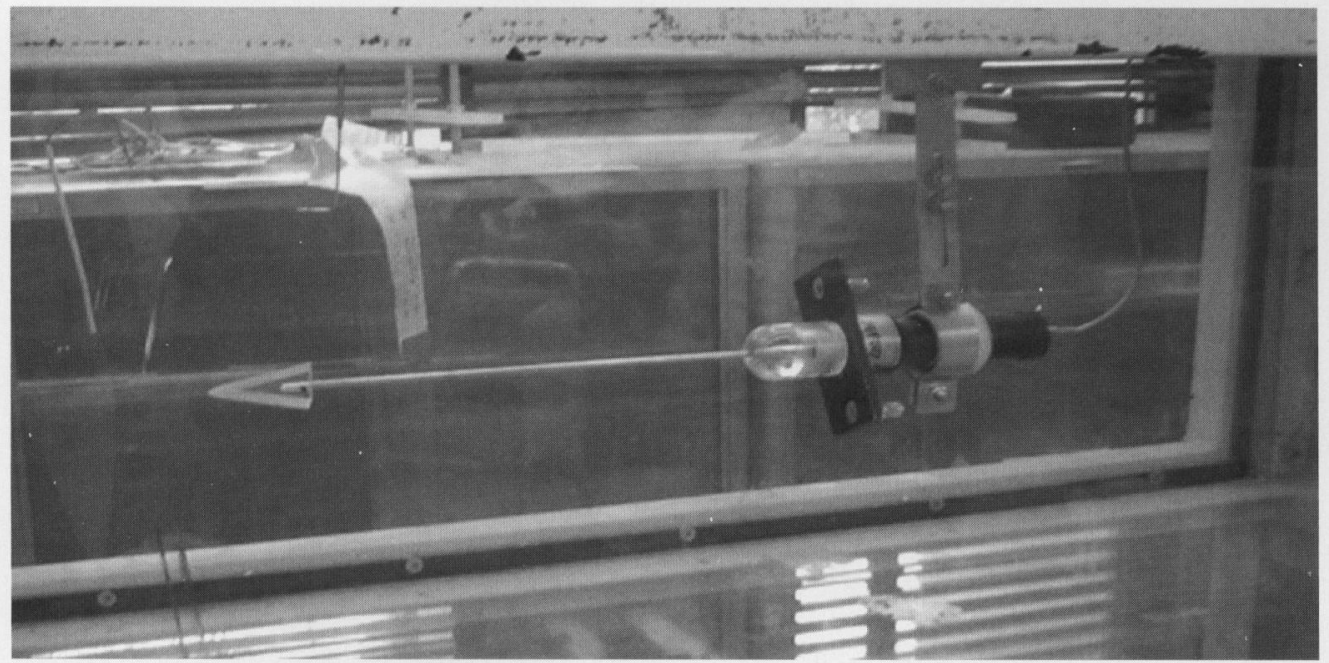

Figure 9. A simulated beveled projectile point in the low-power wind tunnel at California State University Long Beach.

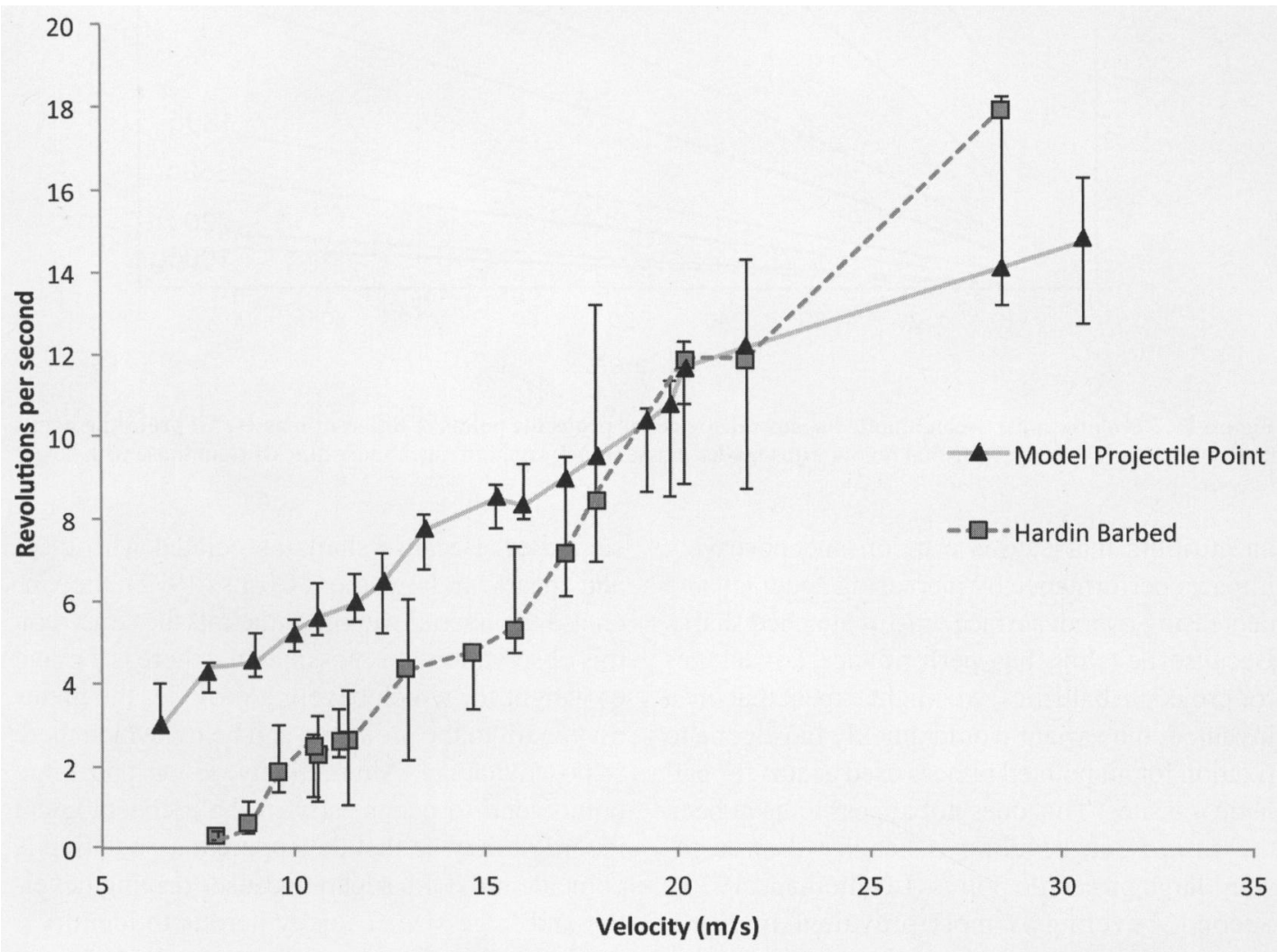

Figure 10. Revolutions per second measured in wind-tunnel experiments on a model projectile point (triangles) and a Hardin Barbed point (squares). 


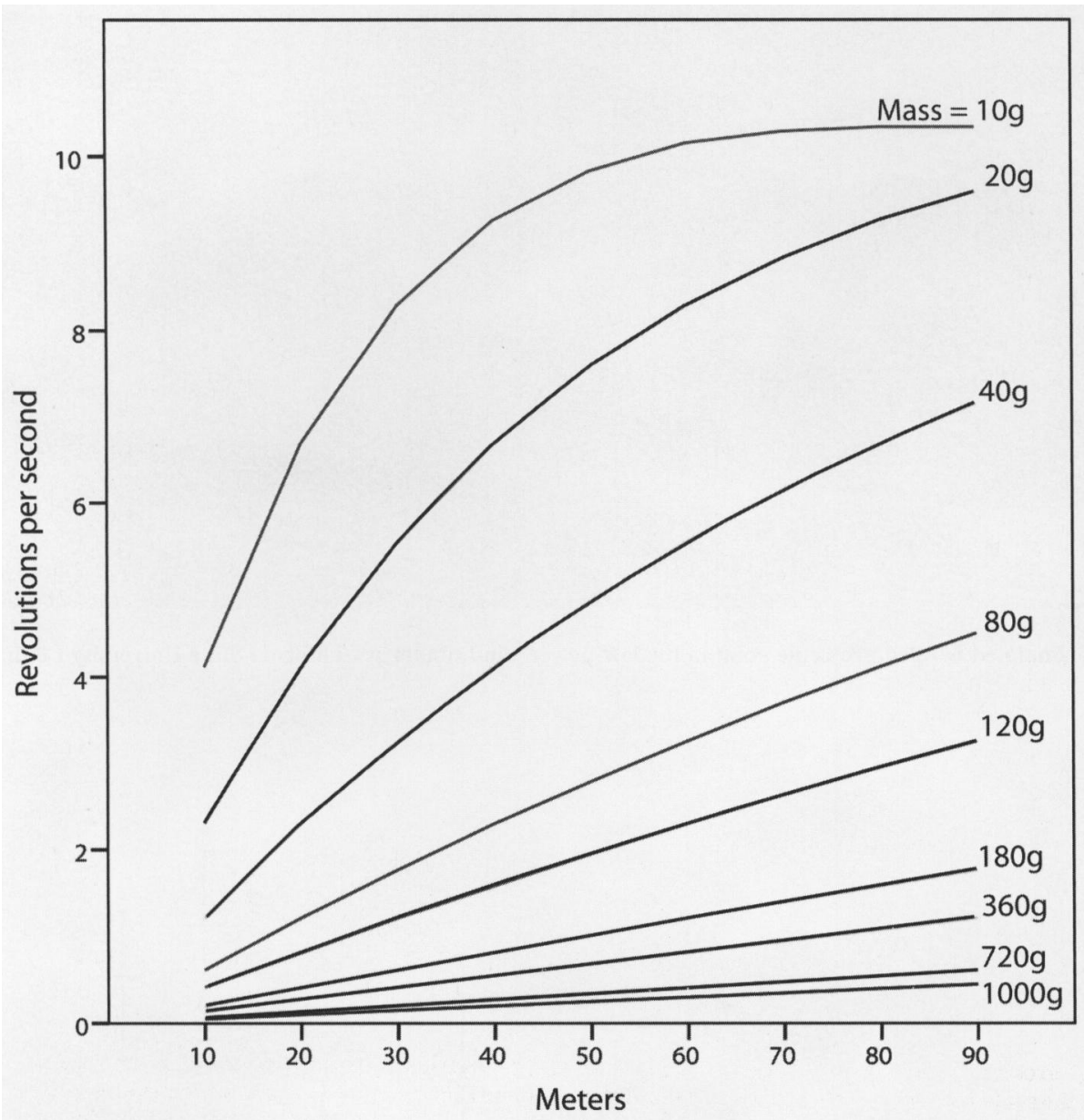

Figure 11. Revolutions per second plotted against distance for projectile points of different masses. All projectile points start with $30 \mathrm{~m} / \mathrm{s}$ velocity. Note that points with smaller masses reach rotation much more quickly than those with larger masses.

an attribute that causes rotation and positively impacts performance by increasing accuracy and decreasing overall surface drag of attached shafts. Because beveling has performance advantages for projectile ballistics, we might expect that once invented, the variant would quickly have gone to fixation for all pointed bifaces used as tips for ballistic missiles. This does not appear to have been the case. First, beveling is heavily skewed toward large projectile points (Luchterhand 1970). Second, beveling is most prevalent in North America during the Early Archaic period and is found only sporadically thereafter, often when the association with ballistic missiles is doubtful (O'Brien and Wood 1998).

Although beveled points tend to be large, size may not be the key feature. Mass is a more likely candidate. Because shafts associated with darts and spears are large (e.g., Corliss 1972), they increase the overall weight of the missile. Based on this observation, it is possible that there is a range of weight for which beveling provides the greatest benefit to the projectile and below which there is no advantage. Alternatively, given that large points tend to occur early in the archaeological record, it may be that the apparent association is coincidental, with separate causes driving beveling and large size. The key here is to identify a mechanism that links mass to rotation and also explains the association between size and beveling in ballistic tips.

Weight of the projectile has its greatest impact on the acceleration of rotation. Larger shafts and pile masses have greater inertia that must be over- 


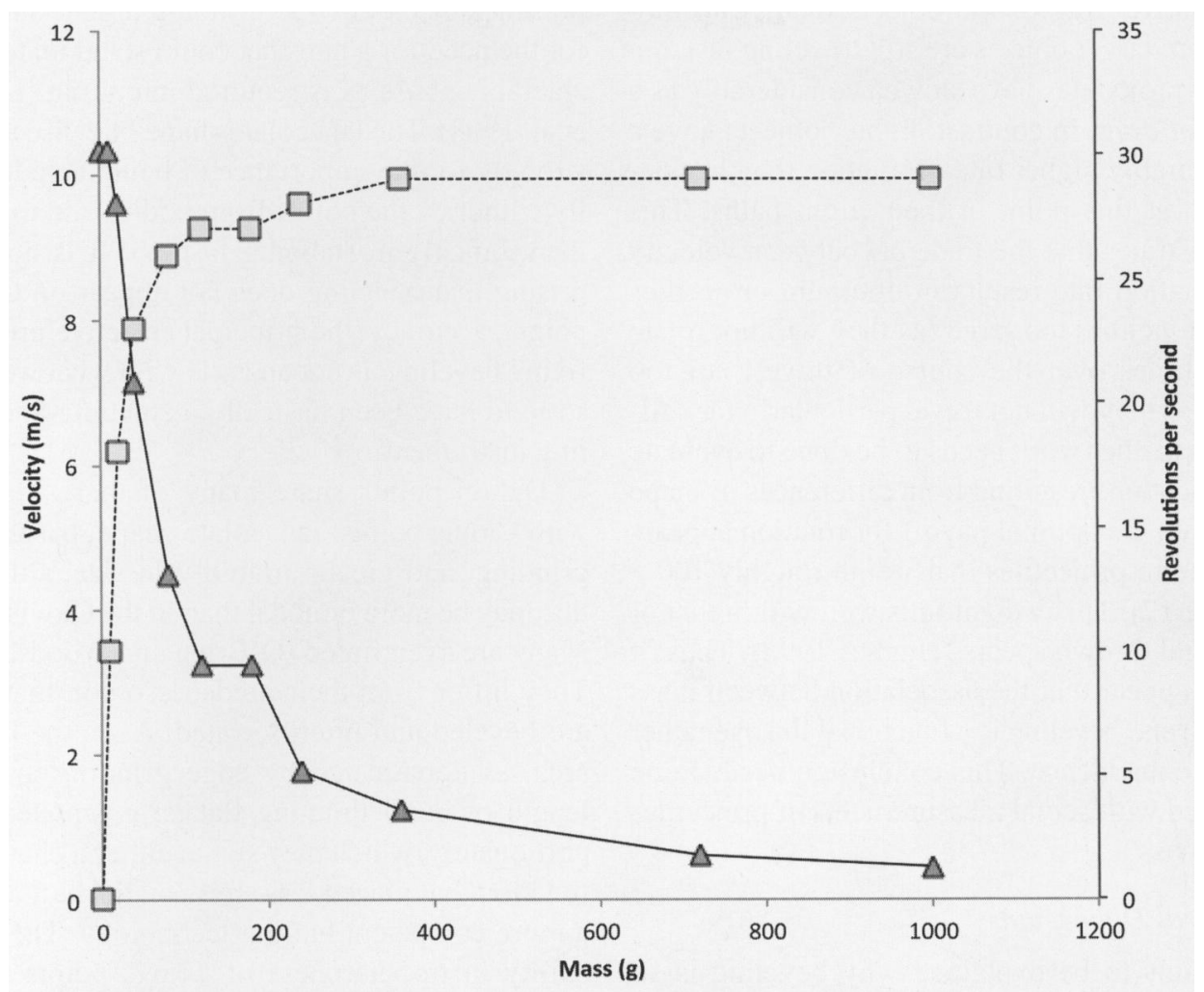

Figure 12. Revolutions (triangles) and velocity (squares) after 10 meters for projectile points of varying mass. All points begin with the same velocity. Lighter points have a high spin rate but low velocity due to low momentum relative to drag. Heavier points have high velocity but low spin. Projectile points around $100 \mathrm{~g}$ (shaded area) provide the best payoff in terms of velocity and rotation rate.

come. So, while larger and heavier projectiles will rotate in the same way as smaller projectiles, their rotation rate will increase more slowly. We can demonstrate this effect by simulating the rotation of projectiles over time, given the same physical configurations and starting speed but varying the mass of the pile. We can iteratively calculate the rotation rate over time by using the principle that angular acceleration is equivalent to torque divided by the moment of inertia. Figure 11 presents the results from this simple model. As expected, the rotation rate is inversely correlated with mass: Heavier masses increase rotation more slowly than lighter masses.

Lighter projectiles reach their terminal spin rate faster than heavier projectiles, but they also have lower momentum relative to drag. Thus, given the same launch velocity, lighter objects travel less distance than heavier projectiles (compare the distance traveled for a thrown soda straw versus a shovel). The shorter the distance that a projectile travels serves to compensate for the loss of accuracy resulting from the lack of rotation. As projectiles get heavier, however, their momentum increases relative to overall drag, resulting in longer flight times and longer distances traveled. In these cases, rotation will make a greater contribution to accuracy. Objects that have masses that are too large, however, will have decreasing rates of rotational acceleration, such that there will be too few rotations before impact to affect accuracy positively.

Figure 12 demonstrates the relation between velocity and rotation. In this example, we measure the rotation and velocity of projectiles of varying masses after they have traveled a distance of $10 \mathrm{~m}$ 
from their launch point with the same initial speed. Velocity at any position is determined by the relative drag of the objects relative to momentum: larger objects are still traveling fast, but lighter projectiles have slowed considerably as a result of drag. In contrast, lighter objects have a considerably higher rate of rotation than heavier objects at this point in their flight paths. This demonstrates that the trade off between velocity and rotation rate results in optimum projectiles that are neither too large (as they will not rotate many times over the course of travel) nor too small (as they will not travel particularly far). Although further work needs to be done to evaluate complications resulting from differences in shape and drag, the optimal payoff for rotation appears to come in projectiles that weigh roughly $100 \mathrm{~g}$ (Figure 12). This weight falls well within that of darts and thrown spears (Hughes 1998). Thus, it would appear that the association between mass ("size") and beveling is a functional linkage rather than a coincidence. This conclusion needs to be explored with actual measurements of projectilepoint mass.

\section{Temporal Dimensions}

It remains to be explained why beveling is so widespread in the Early Archaic period and only incidentally after that. Beveling first appears with Dalton points ca. 11,900 cal B.P., not all of which are beveled (unbeveled points were initially called Meserve points) and which come in many regional (e.g., Hardaway) and temporal (e.g., Searcy) variants. Gradually, with numerous intermediate forms, two successive lineages of points develop from this Dalton base, a notched branch (e.g., Thebes, St. Charles, and Lost Lake) and a stemmed branch (e.g., Hardin and Bolen).

Although a definitive functional analysis of early projectile points has yet to be carried out, the following hypotheses seem plausible based on current data. The Clovis point and its variants, the precursors of the projectile points discussed here, appear to have functioned like a Paleoindian "Swiss Army knife," that is, while the characteristic bilateral symmetry argues strongly for a casting function, its great variability in size, especially length, tip sharpness (often quite blunt), and other characters makes it clear that Clovis points did work in actions such as stabbing and cutting. This is not surprising, given the large body size of the prey being pursued (see Churchill 1993). The presence of basal-edge grinding argues strongly for the need for a haft that could stand up to considerable abuse as is required in cutting (Lyman et al. 1998). The lanceolate shape likewise argues strongly for the importance of being able to easily withdraw the points from bodies and to reuse them quickly in stabbing fashion. It is not surprising that beveling does not appear on Clovis points; accuracy, the principal selective pressure fixing beveling, is not an issue with what we construe to have been basically a stabbing-and-cutting instrument.

Dalton points share many of these features with Clovis points: lanceolate shape, basal-edge grinding, and great variability in size, although this may be more bimodal than in the Clovis case. Many are even fluted (O'Brien and Wood 1998). They differ from their predecessors in that they are beveled and often serrated. Also, the hafted area, as demarcated by edge grinding and the length of basal thinning flakes, is smaller proportionately, which may signal either a change in function that placed less stress on the haft and/or a more competent hafting technology. The variability in tip sharpness of Clovis points is replaced by a single mode skewed toward a highly acute tip angle, although many broken Daltons were reworked into scrapers and other tools, and Dalton-type hafts are common on an expanded range of bifacial tools such as drills, either as a consequence of reworking or as originally manufactured (Goodyear 1974; Shott and Ballenger 2007). Thus, the conditions under which an innovation such as beveling occurred appear to have been part of a broader trend toward increasing functional specificity within bifacial tools, specifically the evolution of a true projectile point, the principal function of which was to tip cast projectiles as opposed to hand-held spears.

This scenario addresses only the appearance of beveling. Its abrupt decline also needs to be explained. An obvious possibility is that some change in casting technology made rotation less advantageous or, alternatively, rotation was achieved by some other means. Reduced accuracy has a very low a priori probability of enhancing fitness so long as casting remains the primary function. Nonetheless, if some other innovation, 
itself incompatible with rotation, conferred even greater benefit, then beveling might be lost even in casting tools. If the function did change, it should be obvious from other changes in successor point design and use. This does not appear to be the case, as many beveled-serrated forms (e.g., Lost Lake) grade smoothly into sequent forms (e.g., Kirk). Perhaps projectile rotation was accomplished by some other mechanism, such as fletching. If fletching were responsible, however, one might expect to see a concurrent reduction in the size of projectile points. The large size of early points is best attributed to the need to locate the center of gravity of the whole projectile forward of the midpoint to prevent tumbling. Fletching solves this problem differently by providing lift at the rear of the projectile.

These possibilities cannot be resolved at the present time; more data on projectile-point design, use-wear characteristics, and breakage patterns, as well as information on the shafts to which they were attached and any machines used in casting, are required. The point here is that quite a number of plausible mechanisms exist to account for the apparently rapid disappearance of beveling.

\section{Conclusions}

We have shown that beveling causes pointed bifaces to spin in flight. This has been demonstrated both theoretically and by wind-tunnel experimentation. In-flight rotation offers benefits in the form of increased accuracy for ballistic shafts that have a mass range consistent with thrown spears and atlatl-launched darts sufficient to explain the fixation of the trait. Further, larger and smaller projectiles do not gain a sufficient benefit from rotation to fix these features as parts of ballistic systems.

In the cultural context of the midwestern and southeastern United States, beveling appears to be an early, if not the first, adaptation to transform the long-handled knife/stabbing tool represented by the Clovis point and its kin into an efficient casting instrument. Other modifications to the ballistic system near the end of the Early Archaic period, ca. 10,000 cal B.P., made beveling superfluous. The precise nature of those modifications, however, remains elusive for want of data on pro- jectile-point variability and chronology. We hope our experimental work will stimulate others to generate the data necessary to further test the hypotheses proposed here.

Acknowledgments. The authors thank Tim Hunt for his ideas on biface variability and Hamid Rahai for his assistance with the California State University Long Beach wind tunnel. M. J. Shott, R. L. Lyman, P. Bleed, and A. Rautman provided numerous insights and suggestions that greatly improved the manuscript. M. D. Dunnell provided editorial assistance.

\section{References Cited}

Abbott, Charles. C.

1877 The Classification of Stone Implements. American Naturalist 9:495-496.

1881 Primitive Industry: Or Illustrations of the Handiwork, in Stone, Bone and Clay, of the Native Races of the Northern Atlantic Seaboard of America. Bates, Salem, Massachusetts.

Acheson, David J.

1990 Elementary Fluid Dynamics. Oxford University Press, New York.

Beckwith, Hiram Williams

1879 Historic Notes on the Northwest. Hill, Chicago.

Bettinger, Robert. L., and Jelmer Eerkens

1999 Point Typologies, Cultural Transmission, and the Spread of Bow-and-Arrow Technology in the Prehistoric Great Basin. American Antiquity 64:231-242.

Blitz, John H.

1988 Adoption of the Bow in Prehistoric North America. North American Archaeologist 9:123-145.

Carr, Lucien, and Nathaniel Southgate Shaler

1876 On the Prehistoric Remains of Kentucky. Memoirs of the Kentucky Geological Survey 1(4).

Christenson, Andrew L.

1986 Projectile Point Size and Projectile Aerodynamics: An Exploratory Study. Plains Anthropologist 31:109-128.

Churchill, Steven E.

1993 Weapon Technology, Prey Size Selection, and Hunting Methods in Modern Hunter-Gatherers: Implications for Hunting in the Palaeolithic and Mesolithic. In Hunting and Animal Exploitation in the Later Paleolithic and Mesolithic of Eurasia, edited by G. L. Peterkin, H. M. Bricker, and P. Mellars, pp. 11-24. Archeological Papers No. 4. American Anthropological Association, Washington, D.C.

Collins, Michael. B.

2007 Discerning Clovis Subsistence from Stone Artifacts and Site Distributions on the Southern Plains Periphery. In Foragers of the Terminal Pleistocene, edited by R. B. Walker and B. N. Driskell, pp. 59-87. University of Nebraska Press, Lincoln.

Corliss, David Williams

1972 Neck Width of Projectile Points: An Index of Culture Continuity and Change. Occasional Papers 29. Idaho State University Museum, Pocatello.

Fairbank, Frederick Royston

1864 On Some Flint Arrow-heads from Canada. Anthropological Review 2:lxiv-lxv.

Fowke, Gerard

1902 Archaeological History of Ohio: The Mound Builders and Later Indians. Ohio State Archaeological and Historical Society, Columbus. 
Goodyear, Albert C.

1974 The Brand Site: A Techno-functional Study of a Dalton Site in Northeast Arkansas. Research Series No. 7. Arkansas Archeological Survey, Fayetteville.

Holmes, William Henry

1896 Prehistory Textile Art of Eastern United States. U.S. Bureau of American Ethnology, Thirteenth Annual Report, 1891-92. Washington, D.C.

Hughes, Susan S.

1998 Getting to the Point: Evolutionary Change in Prehistoric Weaponry. Journal of Archaeological Method and Theory 5:345-408.

Hutchings, Wallace Karl

2011 Measuring Use-related Fracture Velocity in Lithic Armatures to Identify Spears, Javelins, Darts, and Arrows. Journal of Archaeological Science 38:1737-1746.

Jones, Charles Colcok

1873 Antiquities of the Southern Indians, Particularly of the Georgia Tribes. Appleton, New York.

Kelly, John Edward, Steven J. Ozuk, Douglas K. Jackson, Dale L. McElrath, Fred A. Finney, and Duane Esarey

1984 Emergent Mississippian Period. In American Bottom Archaeology, edited by Charles John Bareis and James Warren Porter, pp. 128-157. University of Illinois Press, Urbana.

Luchterhand, Kubet

1970 Early Archaic Projectile Points and Hunting Patterns in the Lower Illinois Valley. Reports of Investigations No. 19. Illinois State Museum, Springfield.

Lyman, R. Lee, Michael J. O’Brien, and Virgil Hayes 1998 A Mechanical and Functional Study of Bone Rods from the Richey-Roberts Clovis Cache, Washington, U.S.A. Journal of Archaeological Science 25:887-906.

Lyman, R. Lee, Todd. L. VanPool, and Michael J. O'Brien 2008 Variation in North American Dart Points and Arrow Points When One, or Both, Are Present. Journal of Archaeological Science 35:2805-2812.

2009 The Diversity of North American Projectile-Point Classes, before and after the Bow and Arrow. Journal of Anthropological Archaeology 28:1-13.

Morgan, Lewis Henry

1851 League of the Iroquois. Sage, Rochester, New York.

Morse, Dan. F.

1971 The Hawkins Cache: A Significant Dalton Find in Northeast Arkansas. Arkansas Archaeologist 12:9-20.

O'Brien, Michael J., and W. Raymond Wood

1998 The Prehistory of Missouri. University of Missouri Press, Columbia.
Packard, Alpheus Spring, Jr.

1877 Anthropological News. American Naturalist 11:436-438.

Patterson, Leland W., and John B. Sollberger

1990 The Significance of Beveled Edges on Projectile Points. La Tierra 17(2):7-38.

Sellers, G. E.

1886 Observations on Stone-Chipping. Miscellaneous $P a$ pers Relating to Anthropology from the Smithsonian Report for 1885 , pp. 871-891. Washington, D.C.

Shott, Michael J.

1993 Spears, Darts, and Arrows: Late Woodland Hunting Techniques in the Upper Ohio Valley. American Antiquity 58:425-443.

1997 Stones and Shafts Redux: The Metric Discrimination of Chipped-Stone Dart and Arrow Points. American Antiquity 62:86-101

Shott, Michael J., and Jesse A. M. Ballenger

2007 Biface Reduction and the Measurement of Dalton $\mathrm{Cu}$ ration: A Southeastern United States Case Study. American Antiquity 72:153-175.

Smith, George Arthur

1953 Beveled or "Rotary" Points. American Antiquity 18:269-270.

Sollberger, John B.

1971 A Technological Study of Beveled Knives. Plains Anthropologist 15-16:209-218.

Squier, Epraim G., and Edwin H. Davis

1848 Ancient Monuments of the Mississippi Valley. Contributions to Knowledge 1. Smithsonian Institution, Washington, D.C.

Tait, Lawson

1874 Feathering in Flint Weapons. Nature (July 30, 1874):245.

Thomas, David H.

1978 Arrowheads and Atlatl Darts: How the Stones Got the Shaft. American Antiquity 43:461-472.

Wallace, Alfred Russel

1887 American Museums: Museums of American Pre-historic Archaeology. Fortnightly Review 42:665-675.

Wilson, Thomas

1898 Beveled Arrowheads. American Archaeologist 2:141-143.

Submitted February 12, 2011; Revised May 6, 2011; Accepted June 7, 2011. 